\title{
SEED GERMINATION OF Avicennia marina (Forsk.) Vierh. BY PERICARP REMOVAL TREATMENT
}

\author{
HERY PURNOBASUKI ${ }^{*}$ and EDY SETITI WIDA UTAMI \\ Department of Biology, Faculty of Sciences and Technology \\ Universitas Airlangga, Surabaya 60115, Indonesia
}

Received 12 November 2013/Accepted 28 September 2016

\begin{abstract}
Avicennia marina is one species used for building coastal ecosystem stabilization in Surabaya shores because of its tolerance to high salinity level and resistance to wave energy. Their existence is threatened by various factors i.e. land conversion, pollution and interisland bridge existence. Growth of $A$. marina is currently limited by seed dormancy. In an effort to increase propagation efficiency, seed viability and vigor were compared based on collection dates and pericarp removal methods. The results showed no relationship between salinity levels of soaking water or seed buoyancy and seed viability or seed vigor. Collection dates may influence seed viability and vigor. Seeds collected in October and November germinated more quickly than those collected in December, although there were no differences in total germination. Hand-peeled seeds germinated more slowly than soaked seeds for all collections, but with no differences in total germination. Seeds collected in October and November grew more vigorously than those collected in December.
\end{abstract}

Keywords: Avicennia marina, propagation eficiency, seed viability

\section{INTRODUCTION}

Avicennia marina (the gray mangrove) produces recalcitrant seeds, dispersed by tidal currents. The dispersal unit or propagule of $A$. marina is the fruit, which usually consists of a single embryo surrounded by a thin pericarp (Tomlinson 1986). The fruit is considered to be cryptoviviparous, a condition where the hypocotyl does not enlarge sufficiently to rupture the pericarp while attach to the parent (Hutchings \& Saenger 1987). Seeds of $A$. marina are cryptoviviparous and do not have a dormant stage resulting in germination possibility while still attach to the parent plant (Tomlinson 1986; Farnsworth 2000). A. marina seeds possess a hydrophilic pericarp, which seed is abscised, shed upon contact with water (Tomlinson 1986). The seeds are dispersed tidally and may remain viable while afloat in agitated seawater for up to one year, although viability decreases over time (USDA 2009).

Typical $A$. marina seed germination initiates when a propagule comes to rest on a suitable

\footnotetext{
* Corresponding author: hery-p@fst.unair.ac.id
}

substrate such as tidal mud flat, beach or within a Spartina spp. marsh (Lewis 2000). This epigeal germination is first observed with the extension of a geotropic root radical into the soil where the seed comes to rest. The hypocotyl extends to become a vertical stalk supporting the cotyledon (Tomlinson 1986). The propagule then extends its epicotyl, from which the first true leaves emerge, allowing the plant to independently photosynthesize the seed. The cotyledons are then desiccated and abscised (Tomlinson 1986).

Seed germination is controlled by a number of mechanisms and is necessary for growth and development of the embryo, resulting in the eventual production of a new plant. Under unfavorable conditions, seeds may become dormant (secondary dormancy) to maintain their germination ability. However, when the conditions are favorable, seeds can germinate (Miransari \& Smith 2014). Among factors controlling seed germination and dormancy is seed pericarp removal (Sari et al. 2006). Seed pericarp is responsible for seedcoating dormancy, affecting seed germination and seedling establishment by preventing water 
absorption, producing chemical inhibitors, preventing leaking of inhibitors from the seed and inhibiting the radical protrusion (Simpson 1990; Baskin \& Baskin 1998; Ogawa \& Iwabuchi 2001; Takos 2001; Sari et al. 2006). The effect of the pericarp on germination depends on seed size and water availability (Chaccon \& Bustamante 2001).

Reproductive success in plants is highly dependent on the survival of their seeds during dispersal. The conditions in which seeds reside after leaving the parent tree towards establishment, and the adaptations of seeds for surviving these conditions are crucial. Seedling establishment is considered difficult for mangroves because of the unstable and varied substrates as well as tidal influence (Tomlinson 1986). Hydrological regimes are particularly important in controlling the survival and subsequent growth of the mangrove seedlings (Murray et al.2003).

Mangrove habitats in Surabaya shores are currently vulnerable to subsidence and sea level rise. As the integrity of coastal salt marsh in Surabaya degrades, $A$. marina habitat is threatened by many activities such as land conversion, pollution and interisland bridge existence. As a result, mangrove stands may be permanently inundated or drained; neither of which are conducive to survival and establishment.

The objectives of this research were to determine the optimal time to collect seeds and the pericarp removal methods to support the highest germination rate and to obtain the most vigorous seedling growth of Avicennia marina.

\section{MATERIALS AND METHODS}

\section{Seed Source}

Avicennia marina seeds were collected from mature trees near Suramadu Bridge, Surabaya (Fig. 1) on 15 October 2011, 15 November 2011 and 15 December 2011. Five hundred and fifty (550) seeds were transported in dry buckets to the Biology Department, Universitas Airlangga and were maintained indoors at room temperature for 24 hours. The day of seed collection was assigned as day zero for all timedelineated treatments.

\section{Seed Preparation}

Two treatments were applied to the seeds, one day after being collected. The two treatments were: 1. seeds pre-soaked in seawater having various levels of salinity until the pericarps were self-removed, and 2. hand-peeled dry seeds.

In the first treatment, there were 5 levels of seawater salinity i.e. $0,5,10,15$ and 20 ppt. Instant sea salt was used to make these levels of salinity. Ten seeds were immersed in each of salinity level on the first day after seeds collection (Day 1). The intention of seeds immersion was to self-remove the pericarps and to establish seeds

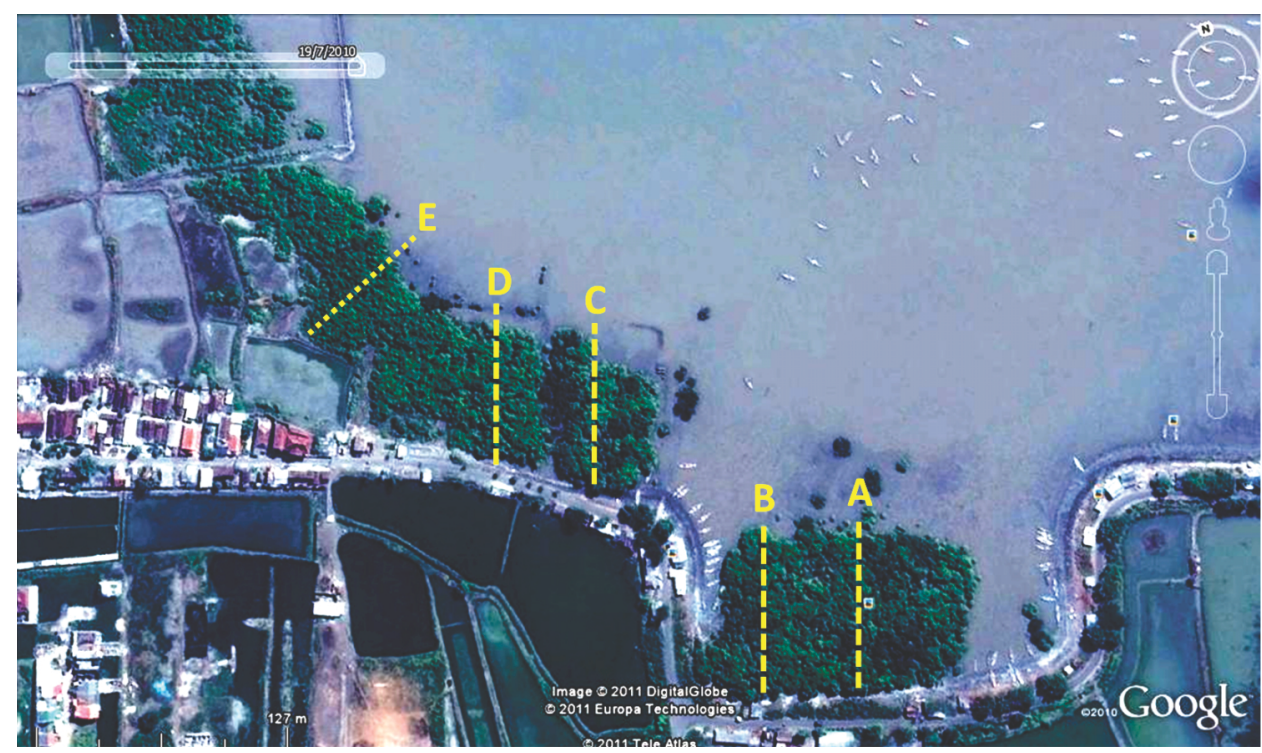

Figure 1 Sampling locations for $A$. marina seed harvests (A, B, C, D and E) near Suramadu bridge 
buoyancy. Seeds buoyancy was determined after 48 hours. Based on the buoyancy, seeds were categorized as floaters or sinkers.

In the second treatment, pericarps of 5 seeds were hand-peeled on Day 1. The peeled seeds were categorized as peeled.

After the pericarps were removed in the first and second treatments, the seeds were weighed and measured along the longest axis.

\section{Seed Planting}

Prior to planting, individual polybags $(7.5 \times 22$ $\mathrm{cm})$ were filled with planting media consisted of sphagnum moss and Vermiculite mix. Polybags were placed in raceway tables in a greenhouse at the Biology Department of Universitas Airlangga. The raceway tables were kept submerged in seawater allowing planting media to be saturated with seawater prior to planting, thus simulating natural germination conditions (Alleman \& Hester 2010). Thermometers were placed in between the submerged raceway tables and at the ends of the tables. Water temperature was recorded within 30 minutes interval for the duration of the study. Air temperature was maintained between 35 and $37{ }^{\circ} \mathrm{C}$ using thermostat-controlled heaters and exhaust fans. The pericarp-peeled seeds were placed on top of the planting media. One seed was placed in each polybag located on raceway tables. Each seed was placed similarly oriented, standing vertically to facilitate equal growth of the radicle into the planting medium.

\section{Seed Germination}

To determine the effect of seed collection dates on seed germination, the percentage of seeds germination was compared based on seed collection dates and the seed treatments i.e. handpeeled, floater $(0 \mathrm{ppt})$ and sinker $(0 \mathrm{ppt})$. Five replications were applied to compare the percentage of seeds germination. The comparison was carried out on Day 48 i.e. on 15 March 2012 to allow the earliest planting of $A$. marina in Surabaya coastal area.

\section{Germination Rate}

Avicennia marina produces cryptoviviparous propagules which means that embryonic axis/hypocotyl of the developing embryo does not penetrate the seed coat. Therefore, seed germination was recorded when the epicotyl's true leaves were visible beyond the cotyledon (Fig. 2). Propagule viability was recorded daily for the first 28 days for each treatment by observing the vigor and growth. Germination rate is determined by calculating the germination percentage of different time interval after planting and then plotting these data. The cumulative germination over time was compared among treatments. The germination rate of each treatment was calculated using formula as follows (Ranal \& De Santana 2006):

Germination rate $=\frac{\text { number of normal seedling }}{\text { days to first count }}+\frac{\text { number of normal seedling }}{\text { days to final count }}$

\section{Germination Percentage}

Germination percentage is the number of germinated seeds from a seed population. Germination percentage of seeds was compared among treatments after 28 days of study. Percentage of seed germination was calculated for each replication, from which the average was calculated for each treatment.

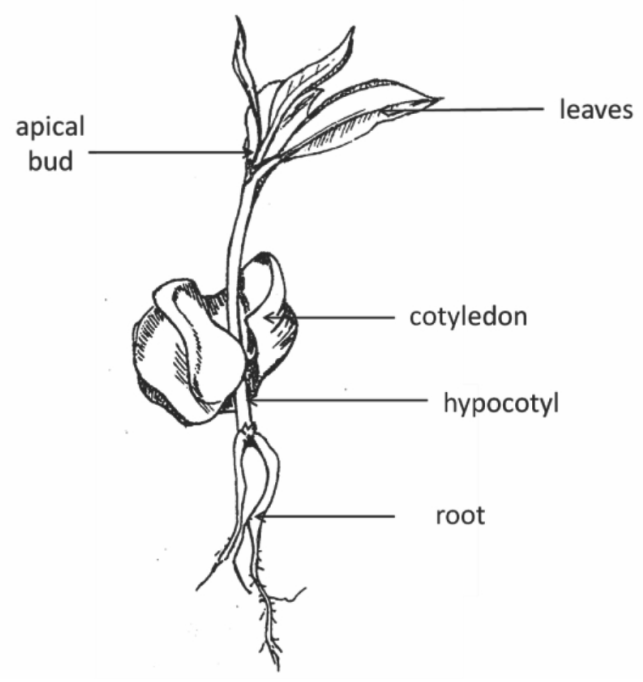

Figure 2 Basic post-germination anatomy of an Avicennia marina propagule (Crumbie 1987)

\section{Seedling Vigor}

Seedling vigor was quantified by measuring seedling height $(\mathrm{mm})$ and stem length $(\mathrm{mm})$ from the soil surface to the terminal bud. Mean height of plants for each seed collection date was measured three times during the growing period. Seedlings from seeds collected in October were 
measured at 62, 75 and 165 Days Since Collected (DSC). Seedlings from seeds collected in November were measured at 43, 70, 92 and 133 DSC and seedlings from seeds collected in December were measured at 79, 104 and 126 DSC. Seeds that had not germinated were not included in the seedling vigor analysis.

\section{Data Analysis}

Analysis of variance (ANOVA) and Duncan's Multiple Range Test (DMRT) at $p<0.05$ were carried out for data analysis. Data were analyzed using MS Excel and SPSS version 10 to explore possible treatment variations. ANOVA was carried out to determine the treatments effects on seed germination percentage as well as on height and diameter of the seedlings. DMRT was used to compare the mean of germination percentage, height and diameter in each pre-sowing treatment.

\section{RESULTS AND DISCUSSION}

Seed germination is a response characterized by three parameters i.e. percentage, rate, and uniformity (Hartmann et al. 2002). Germination percentage is the number of germinated seeds from a seed population. Germination rate is the "speed or velocity" of germination and can be expressed as the time needed for a defined percentage of seed to germinate. Germination uniformity is a measurement of the time needed for all seeds to germinate. The mean weight and length of seeds among the treatments varied slightly (Table 1). However, the largest and the smallest seeds were sinkers and there was no evidence of seed size effect among treatments. Germination percentage was not linear over time and became asymptotic after 40 days of seeds collection (Fig. 3). After 28 days, the hand-peeled seeds treatment had the lowest (21\%) germination percentage (Fig. 3 and 4). Germination rates for the floaters and sinkers soaked in 0 ppt treatments were not different from those soaked in other salinity levels. Therefore, the subsequent germination trials only used seeds soaked in 0 ppt salinity and handpeeled seeds for pericarp removal (Fig. 3).

Seed size is commonly used as an indicator of seed viability and vigor for many plant species (Murali 1997), but the relationship is highly varied and therefore, typically abandoned as reliable indicator outside agricultural applications. Seed size and buoyancy have been examined in mangrove species as indicators of seedling performance, but primarily as factors influencing seed dispersal (Rabinowitz 1978a, 1978b, 1978c). The studies of Rabinowitz (1978a) suggested that the buoyancy and seed size of Avicennia and other mangrove species may determine the zonation of seed deposition, but make no indication of viability and vigor. In this study, although seed size varied slightly, there were no differences in germination rate among seed sizes. Therefore, selection of $A$. marina seeds were not differentiated by size.

Table 1 Mean $( \pm$ SE) of seed weight $(\mathrm{g})$ and length $(\mathrm{mm})$ for seeds collected in October

\begin{tabular}{cccc}
\hline \multirow{2}{*}{ Treatment } & & Weight $(\mathrm{g})$ & Peeled \\
\cline { 2 - 4 } & Floaters & Sinkers & \\
\hline $0 \mathrm{ppt}$ & $4.1 \pm 0.08^{\mathrm{ab}}$ & $3.9 \pm 0.37^{\mathrm{ab}}$ & \\
$5 \mathrm{ppt}$ & $4.4 \pm 0.23^{\mathrm{ab}}$ & $4.5 \pm 0.15^{\mathrm{ab}}$ & \\
$10 \mathrm{ppt}$ & $4.1 \pm 0.10^{\mathrm{ab}}$ & $3.2 \pm 0.22^{\mathrm{b}}$ & \\
$15 \mathrm{ppt}$ & $3.9 \pm 0.09^{\mathrm{ab}}$ & $3.6 \pm 0.24^{\mathrm{ab}}$ & \\
$20 \mathrm{ppt}$ & $3.8 \pm 0.11^{\mathrm{ab}}$ & - & \\
Peeled & - & Length $(\mathrm{mm})$ & \\
\hline & & $29.1 \pm 1.33^{\mathrm{ab}}$ & \\
\hline $0 \mathrm{ppt}$ & $28.9 \pm 0.28^{\mathrm{a}}$ & $28.7 \pm 0.55^{\mathrm{a}}$ & \\
$5 \mathrm{ppt}$ & $29.9 \pm 0.28^{\mathrm{a}}$ & $24.7 \pm 0.89^{\mathrm{b}}$ & $29.4 \pm 0.22^{\mathrm{a}}$ \\
$10 \mathrm{ppt}$ & $28.4 \pm 0.37^{\mathrm{a}}$ & $27.3 \pm 1.02^{\mathrm{ab}}$ & \\
$15 \mathrm{ppt}$ & $27.6 \pm 0.38^{\mathrm{a}}$ & & \\
$20 \mathrm{ppt}$ & $28.7 \pm 0.29^{\mathrm{a}}$ & & \\
Peeled & &
\end{tabular}

Notes: Numbers followed by the same letters in the same column are not significantly different at $p<0.05$ 


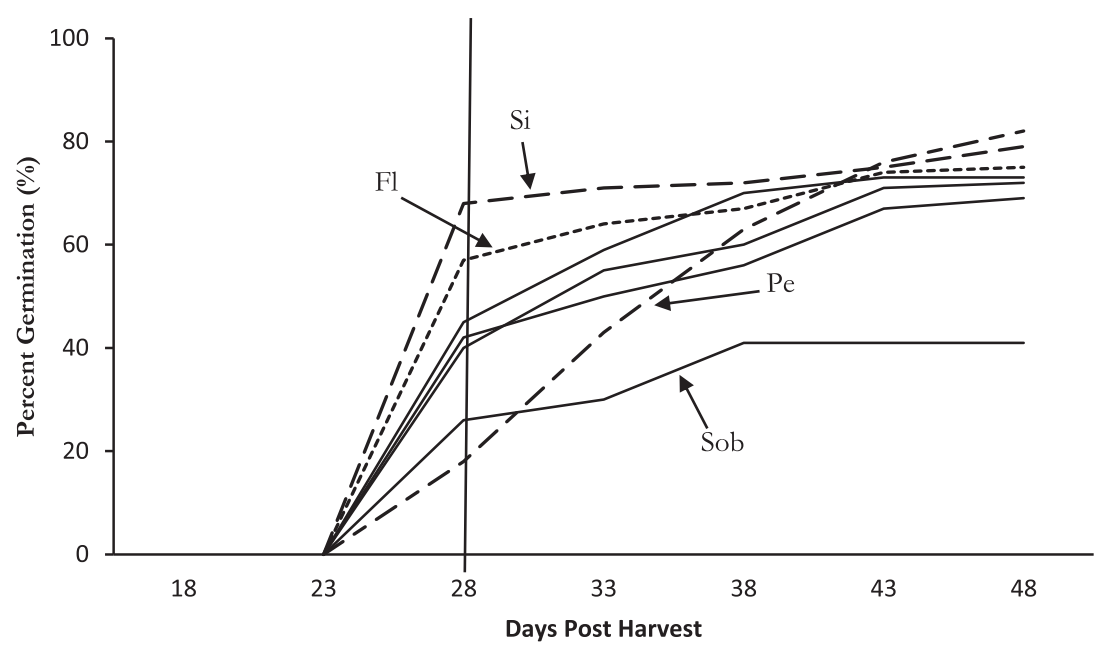

Figure 3 Cumulative germination percentage at 48 DSC (Days Since Collected) for floaters, sinkers and peeled treatments for $A$. marina seeds collected on 1 October $2011 . \mathrm{Si}=$ sinkers exposed to $0 \mathrm{ppt} ; \mathrm{Fl}=$ floaters exposed to $0 \mathrm{ppt} ; \mathrm{Pe}=$ peeled seeds; Sob = combinations of seeds soaked in various salinity levels and buoyancy treatments; vertical line indicates 28 DSC for seeds collected on 1 October 2011

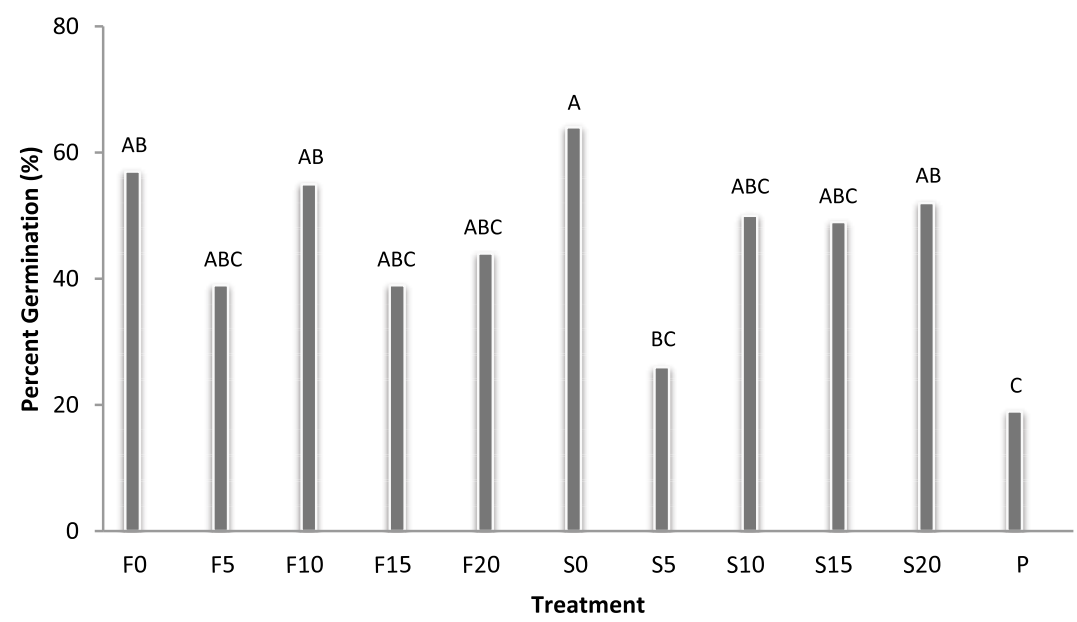

Figure 4 Mean $( \pm$ SE) of germination percentage per treatment in 28 DSC for seeds collected on 1 October 2011. F = floaters; $\mathrm{S}=$ sinkers; $\mathrm{P}$ = peeled seeds; the numbers following either $\mathrm{F}$ or $\mathrm{S}$ represents salinity levels. Bar charts having the same letters on top are not significantly different at $p<0.05$

Germination rates for the floaters and sinkers soaked in 0 ppt treatments were not different from those soaked in other salinity levels. Therefore, the subsequent germination trials only used seeds soaked in 0 ppt salinity level and hand-peeled seeds for pericarp removal (Fig. 3).

Germination percentages of seeds soaked in various levels of salinity were not significantly different. Therefore, treatment comparison for all collected seeds only used seeds soaked in $0 \mathrm{ppt}$ salinity level (Fig. 4).
Mean of seed sizes varied among treatments and collection dates, but there were no obvious trends among pericarp removal treatments, salinity levels or collection dates (Table 2). Germination rate was relatively different for seeds collected in October, November or December (Fig. 5). Seeds collected in October germinated faster $(78 \%)$ than seeds collected in December (11.3\%) (Fig. 6). However, on 15 March 2012 (48 DSC), the averages of germination percentage were different among treatments (Fig. 7). 
Table 2 Mean $( \pm \mathrm{SE})$ of seed length $(\mathrm{mm})$ and weight $(\mathrm{g})$ for floaters $(0 \mathrm{ppt})$, sinkers $(0 \mathrm{ppt})$ and peeled seeds for seeds collected in October, November and December

\begin{tabular}{lccc}
\hline Treatment & \multicolumn{3}{c}{ Collected in } \\
\cline { 2 - 4 } & October & November & December \\
\hline Floaters & $29.6 \pm 0.28^{\mathrm{ab}}$ & $31.2 \pm 0.29^{\mathrm{a}}$ & $28.4 \pm 0.42^{\mathrm{b}}$ \\
Sinkers & $29.4 \pm 1.33^{\mathrm{ab}}$ & $29.9 \pm 0.34^{\mathrm{ab}}$ & $29.9 \pm 0.50^{\mathrm{ab}}$ \\
Peeled & $31.2 \pm 0.29^{\mathrm{a}}$ & $29.6 \pm 0.29^{\mathrm{ab}}$ & $30.7 \pm 0.31^{\mathrm{ab}}$ \\
\hline & & & \\
\hline & & Weight $(\mathrm{g})$ & $2.4 \pm 0.13^{\mathrm{b}}$ \\
\hline Floaters & $3.0 \pm 0.08^{\mathrm{ab}}$ & $3.3 \pm 0.09^{\mathrm{a}}$ & $2.9 \pm 0.12^{\mathrm{ab}}$ \\
Sinkers & $2.9 \pm 0.37^{\mathrm{ab}}$ & $3.0 \pm 0.09^{\mathrm{ab}}$ & $3.2 \pm 0.11^{\mathrm{a}}$ \\
\hline
\end{tabular}

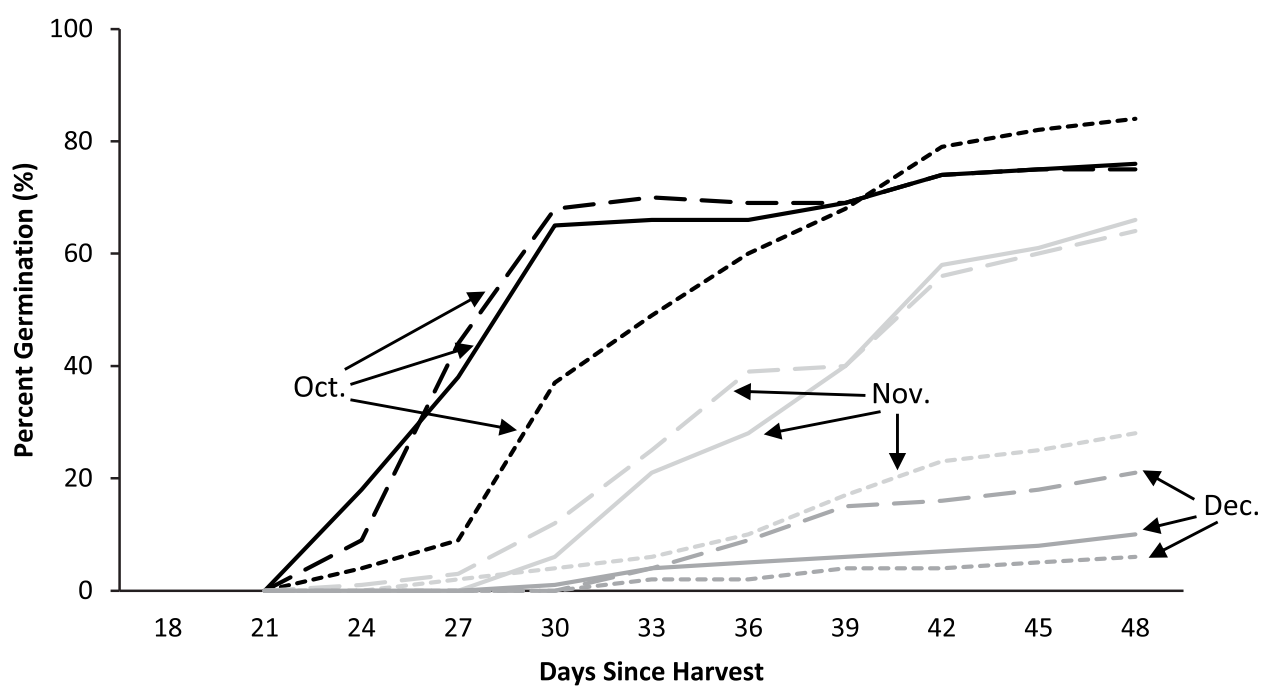

Figure 5 Cumulative germination percentage for seeds collected in October, November and December in 48 DSC, in 0 ppt salinity level. October collection is represented by black lines; November collection is represented by light gray lines; December collection is represented by dark gray lines. Hand-peeled seeds are represented by short dashes, floaters are represented by solid lines and sinkers are represented by long dashes

Seeds peeling to expose embryos have been carried out by other researchers in different experiments (Arrillaga et al. 1992). Seeds collected in October and November germinated sooner than those collected in December, however, the total germination was not different in 48 DSC. Seeds collected in October and November grew to similar sizes in 48 DSC and both grew more vigorously than those collected in December. Duration and seawater temperature most likely influenced the seed germination and growth rates of seeds collected in December. Further study is warranted to determine the relationship between duration, seawater temperature and propagule performance. Hand-peeled seeds germinated later compared to seeds soaked in various levels of salinity, but with no differences in total germination. The stem length average of handpeeled seed was nominally greater for all seeds collected by 15 March 2012 .

Agitation of soaking seawater at various salinity levels was observed to delay germination in Avicennia germinans (McMillan 1971). The delay of germination displayed in peeled seeds might indicate that there were other stimulus besides immobilization as an initiator of germination in this species, such as seed moisture, pericarp abscission and seed abscission. The potential for delayed germination of cryptoviviparous seed is justification for further investigation. This 


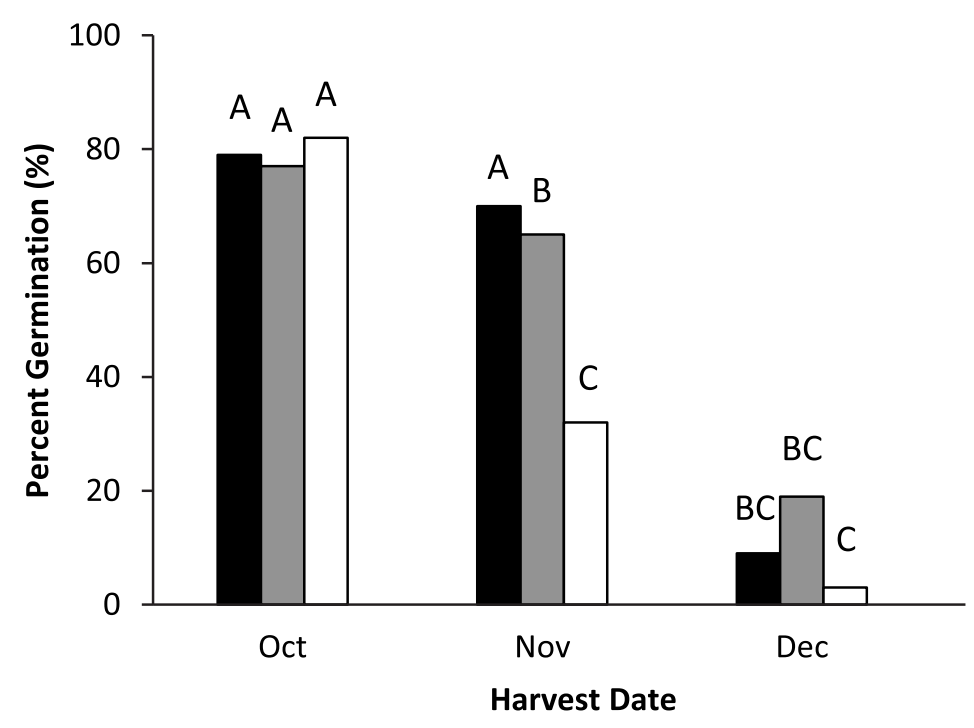

Figure 6 Mean ( \pm SE) of germination percentage of $A$. marina seeds in 48 DSC for seeds collected on 1 October 2011,1 November 2011 and 1 December 2011. Floaters are represented by black bars; sinkers are represented by gray bars; hand-peeled seeds are represented by white bars. Bar charts having the same letters on top are not significantly different at $p<0.05$

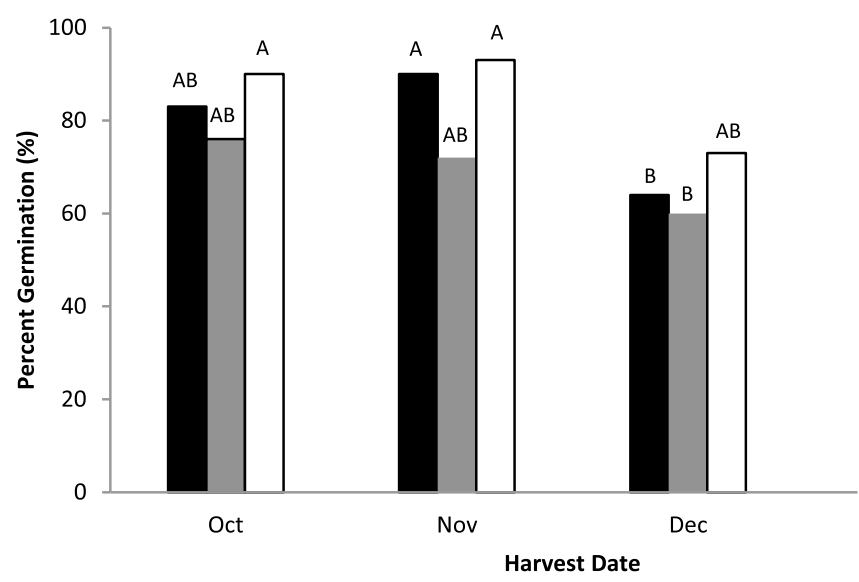

Figure 7 Mean $( \pm$ SE) of germination percentage in 48 DSC for seeds collected on 1 October 2011, 1 November 2011 and 1 December 2011. Floaters are represented by black bars; sinkers are represented by gray bars; hand-peeled seeds are represented by white bars. Bar charts having the same letters on top are not significantly different at $p<0.05$

condition was not consistent with research results of $\mathrm{Hu}$ et al. (2009) who reported that removal of pericarp improved the germination percentage up to $90 \%$ from $44 \%$ in seeds of Hedysarum scoparium and $60-100 \%$ in seeds of Oryza sativa (Miyoshi \& Sato 1997).

Pericarp removal did not provide significant effects on seedling performance in terms of dry masses of epicotyls and roots of seedlings. This result was slightly different from the study results of Liu et al. (2012). This might be caused by mechanical constraints rather than chemical inhibitors. It is generally accepted that epicotyl dormancy of acorns in the field is mainly caused by inhibitors in cotyledons, embryos or pericarps (Liu et al. 2012). This was consistent with most research (Robertson et al. 2006, Finney 2011) who reported pericarp-imposed dormancy on seeds. Our study suggested that pericarp was responsible for seed dormancy because seeds with intact pericarp were very dormant; therefore, removal of the pericarp significantly increased germination percentage and resulted in complete germination of viable seeds. 


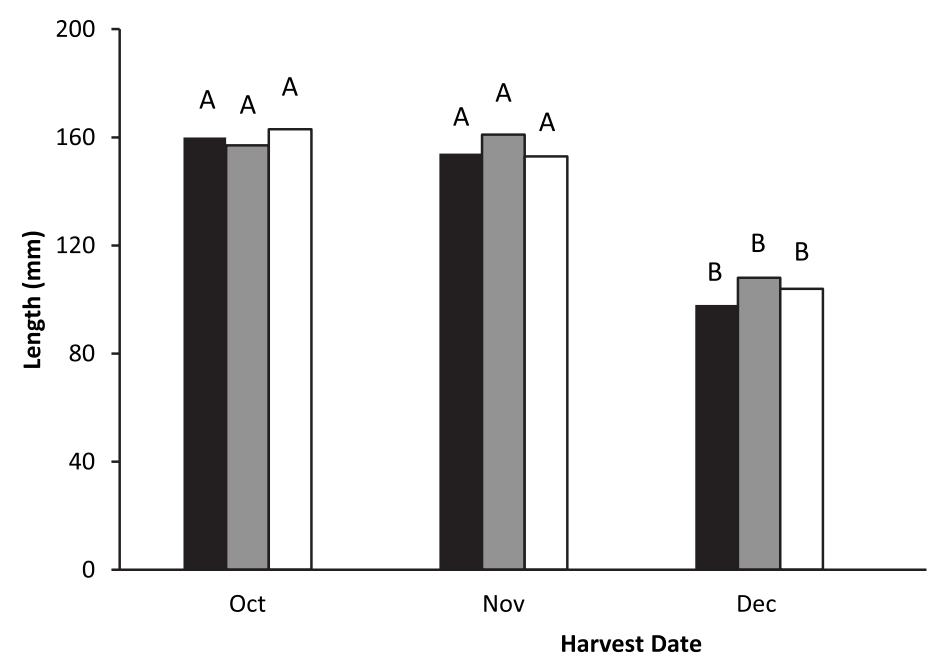

Figure 8 Mean $( \pm \mathrm{SE})$ of seedlings stem length for seeds collected in October, November and December in 48 DSC. Floaters are represented by white bars; sinkers are represented by gray bars; hand-peeled seeds are represented by black bars. Bar charts having the same letters on top are not significantly different at $p<0.05$

The means of seedlings stem lengths for seeds collected in October and November were not significantly different in 48 DSC among treatments. However, seeds collected in December had significantly shorter seedlings stem length in 48 DSC (Fig. 8).

Range of seawater salinity in the mangrove habitats of Surabaya coast is $17-30$ ppt all year round. Seawater salinity can widely vary due to pollution, hurricane and flood which introduce large volumes of seawater or freshwater to the coastal estuaries. The studies of Rabinowitz (1978 a, b, c) and McKee (1995) indicated that the salinity level of the soaking seawater used to immerse seeds might affect viability duration during dispersal. However, results of this study indicated that there were no correlations between buoyancy or salinity level of soaking seawater used to immerse seeds and seed viability or vigor. This study, however, suggested that seeds collection date might influence seed viability and vigor, such as shown in the germination of Avicennia germinans (Finney 2011).

Seeds collection date is commonly used in horticulture and agriculture to predict seed viability and crop yield as well as to observe the relationship between seed maturity and viability (Basra 1995). However, correlations between early and late seed collections are not consistent among species. Seeds collected in later dates and their maturity had been shown to positively influence seed quality and vigor in soybeans Glycine max (TeKrony et al. 1984) as well as other cultivated crops and trees (Basra 1995). Maximum seed viability and vigor occurred earlier in seed maturation for tomatoes Solanum lycopersicum (Demir \& Ellis 1992). Relationships between propagule and seed maturity as well as viability among viviparous mangrove genera are poorly defined (Farnsworth 2000).

This research indicated that salt is not needed in the soaking process to remove pericarp. Seeds collected in earlier date experienced quicker germination and subsequently produced larger plants at the earliest time of field planting. However, longer maintenance was required to grow the seedlings. Seed collected in later date produced smaller plants, but required less greenhouse time with no difference in germination viability. Germination can be delayed for a short time by hand-peeling the pericarps from dry seeds with equal or greater germination and growth rates, however, it requires more labor (Finney 2011).

\section{CONCLUSIONS}

Removal of seed pericarp improved germination. There were no correlations between buoyancy or salinity level of soaking seawater used to immerse seeds and seed viability or vigor. Seeds collection date might influence seed viability and vigor. Seeds collected in October and November germinated more quickly than those collected in December, although there was no 
significant difference in total germination. Seeds collected in October and November had similar growth and both grew more vigorously than those collected in December. Simple alterations in seed treatment can enhance seed germination.

\section{ACKNOWLEDGEMENTS}

We thank Djoko Suwondo for his great support in our field research and Prof Mitsuo Suzuki PhD. for his helpful comments and criticis on the manuscript. We also thank Ade Hermawan and Syaiful Yahya for their field-sampling assistance.

\section{REFERENCES}

Arrillaga I, Marzo T, Segura J. 1992. Embryo culture of Fraxinus ornus and Sorbus domestica removes seed dormancy. Hort Science 27:371.

Alleman LK, Hester MW. 2010. Refinement of the fundamental niche of black mangrove (Avicennia germinans) seedling in Louisiana: applications for restoration. Wetl Ecol Manag 19:47-60.

Baskin CC, Baskin JM. 1998. Seeds: ecology, biogeography, and evolution of dormancy and germination. San Diego, CA (US): Academic Press. 666 p.

Basra AS. 1995. Seed quality: the basic mechanisms and agricultural implications. Binghamton, NY (US): Haworth Press. 376 p.

Chaccon P, Bustamante RO. 2001. Effect of seed size and pericarp on seedling recruitment and biomass in Cryptocarya alba (Lauraceae) under two contrasting moisture regimes. Plant Ecol 152:137-44.

Crumbie MC. 1987. Avicennia marina: the grey mangrove: general notes and observations. Bull Emirates Nat Hist Gr (Abu Dhabi) 32:2-13.

Demir I, Ellis RH. 1992. Changes in seed quality during seed development and maturation in tomato. Seed Sci Res 2:81-7.

Farnsworth E. 2000. The ecology and physiology of viviparous and recalcitrant seeds. Ann Revue Ecol Systematics 31:107-38.

Finney W. 2011. Comparative growth and propagule viability of Louisiana-harvested black mangrove, Avicennia germinans. Master Thesis. Faculty of Sciences in Marine and Environmental Biology, Nicholls State University, Thibodaux, LA (US). 34 p.

Hartmann HT, Kester DE, Davies Jr FT, Geneve RL. 2002. Plant propagation: principles and practices. $7^{\text {th }}$ ed. Upper Saddle River, NJ (US): Prentice Hall. 869 p.
Hu XW, Wang YR, Wu YP. 2009. Effects of the pericarp on imbibition, seed germination, and seedling establishment in seeds of Hedysarum scoparium Fisch. et Mey. Ecol Res 24(3): 559-64.

Hutchings P, Saenger P. 1987. Ecology of mangroves. St. Lucia (AU): University of Queensland Press. 388 p.

Lewis RR III. 2000. Ecologically based goal setting in mangrove forest and tidal marsh restoration. Ecol Engin 15:191-8.

Liu Y, Liu GQ, Li QM, Liu Y, Hou LY. 2012. Influence of pericarp, cotyledon and inhibitory substances on sharp tooth oak (Quercus aliena var. acuteserrata) germination. PLoS One 7(10): e47682.

McKee K. 1995. Seedling recruitment patterns in a Belizean mangrove forest: effects of establishment ability and physico-chemical factors. Oecologia 101:44860.

McMillan C. 1971. Environmental factors affecting seedling establishment of the black mangrove on the central Texas coast. Ecology 52:927-30.

Miransari M, Smith DL. 2014. Plant hormones and seed germination. Environ Exper Bot 99:110-21.

Miyoshi K, Sato T. 1997. Removal of the pericarp and testa of seeds of japonica and indica rice (Oryza sativa) at various oxygen concentrations has opposite effects on germination. Physiol Plant 99(1):1-6.

Murali KS. 1997. Patterns of seed size, germination and seed viability of tropical tree species in southern India. Biotropica 29:271-9.

Murray MR, Zisman SA, Furley PA, Munro DM, Gibson J, Ratter J, Bridgewater S, Minty CD, Place CJ. 2003. The mangroves of Belize Part 1. Distribution, composition and classification. For Ecol Manage 74:265-79.

Ogawa K, Iwabuchi M. 2001. A mechanism for promoting the germination of Zinnia elegans seeds by hydrogen peroxide. Plant Cell Physiol 42(3):286-91.

Rabinowitz D. 1978a. Dispersal properties of mangrove propagules. Biotropica 10:47-57.

Rabinowitz D. 1978b. Mortality and initial propagule size in mangrove seedlings in Panama.J Ecol 66:45-51.

Rabinowitz D. 1978c. Early growth of mangrove seedlings in Panama and an hypothesis concerning the relationship of dispersal and zonation. J Biogeogr 5:113-33.

Ranal MA, De Santana DG. 2006. How and why to measure the germination process. Revista Brasil Bot 29(1):1-11.

Robertson AW, Trass A, Lasley JJ, Kelly D. 2006. Assessing the benefits of frugivory for seed germination: the importance of the deinhibition effect. Funct Ecol 20:58-66.

Sari A, Ogu B, Bilgic A. 2006. Breaking seed dormancy of laurel (Laurus nobilis L.). New For 31:403-8. 
Simpson GM. 1990. Seed dormancy in grasses. New York (US): Cambridge University Press. 297 p.

Takos IA, 2001. Seed dormancy in bay laurel (Laurus nobilis L.). New For 21:105-14.

TeKrony DM, Egli DB, Balles J, Tomes L. 1984. Effect of date of collected maturity on soybean seed quality and Phomopsis sp. seed infection. Crop Science 24:189-93.
Tomlinson PB. 1986. The botany of mangroves. New York (US): Press Syndicate of the University of Cambridge. 419 p.

United States Department of Agriculture (USDA). 2009. Natural resource conservation service. Plant materials center. Plant guide for black mangrove. 1-3. 